\title{
The role of monitoring and evaluation in climate change mitigation and adaptation interventions in developing countries
}

Author:
David Ssekamatte ${ }^{1}$
Affiliation:
${ }^{1}$ Monitoring and Evaluation,
School of Business and
Management, Uganda
Management Institute,
Uganda
Corresponding author:
David Ssekamatte,
dmssekamatte@gmail.com
Dates:
Received: 19 July 2017
Accepted: 30 Oct. 2017
Published: 07 Mar. 2018
smart phone or
mow to cite this article:
to read online.
Ssekamatte, D., 2018, 'The
role of monitoring and
evaluation in climate change
mitigation and adaptation
interventions in developing
countries', African Evaluation
Journal $6(1)$, a254. https://
doi.org/10.4102/aej.v6i1.254
Copyright:
Co 2018. The Authors.
Licensee: AOSIS. This work
is licensed under the
Creative Commons
Attribution License.

Background: Although the role of monitoring and evaluation (M\&E) in enhancing evidencebased management in development work is increasingly recognised, M\&E remains underutilised as a vital tool in informing climate change mitigation and adaptation interventions in many developing countries. Practitioners in climate change mitigation and adaptation interventions are yet to exploit M\&E to enhance effectiveness of their programmes.

Objectives: This article underscores the critical role that M\&E can and should play in enhancing effectiveness of climate change mitigation and adaptation interventions in developing countries. It provides a scholarly look at M\&E and its visibility in climate change mitigation and adaptation work, the evidence of its role in mitigation and adaptation interventions across developing nations and the missing gaps in utilisation of M\&E for mitigation and adaptation. This article presents key insights that practitioners need to design effective M\&E systems for climate change mitigation and adaptation.

Methods: The article was compiled based on Cooper's stages of literature review 1984. A total of 15 peer-reviewed articles, a few eBooks and hard copy textbooks as well as reports from credible international organisations that met the inclusion criteria of focus, goal and coverage on $\mathrm{M} \& \mathrm{E}$ and climate change mitigation and adaptation were reviewed.

Results: The findings show that M\&E can be used as an effective tool for learning, informing evidence-based decision-making, promoting accountability and helping organisations to improve on climate change mitigation and adaptation interventions.

Conclusion: M\&E if well designed and implemented can be handy and useful in informing climate change mitigation and adaptation interventions.

\section{Introduction}

Although the role of monitoring and evaluation (M\&E) in enhancing evidence-based management in development work is increasingly recognised, M\&E remains under-utilised as a vital tool in informing climate change mitigation and adaptation interventions in many developing countries. Practitioners in climate change mitigation and adaptation interventions are yet to exploit M\&E to enhance effectiveness of their programmes. In their preface to the handbook of practical programme evaluation, Wholey, Hatry and Newcomer (2010) argue that:

the demand for program evaluation is growing. Congress, state legislatures, local legislative bodies, public agencies, foundations, nonprofit organizations, and other funding agencies are increasingly demanding information on how program funds have been used and what funded programs have produced. (p. XVII)

This illustrates the critical role that M\&E plays in the implementation of any intervention within any sector. In many developing nations, $\mathrm{M} \& \mathrm{E}$ is a condition that recipients of donor funding in any sector must fulfil. Almost in all project or programme proposals, the donors require a section explaining how M\&E of the funded programme will be done including the nature of data that will be collected, and how it will be analysed and interpreted as well as reported periodically and routinely for purposes of learning, informing implementation and accountability.

Climate change mitigation and adaptation are the key strategies that scientists have prescribed for countries, agencies and organisations as well as individuals in dealing with the climate change 
problem across the globe. Climate change mitigation focuses on interventions to reduce greenhouse gas (GHG) concentrations, while adaptation focuses on the process of decreasing the level of exposure to effects of climate change for both nature and human beings (Allison 2012). Several countries have intervened in dealing with the climate change problem through these two strategies at different levels.

Whatever level of intervention, M\&E would play a key role in enhancing the effectiveness of climate change mitigation and adaptation interventions. However, literature on whether this is happening in developing countries is very scanty and almost non-existent. This was the basis for undertaking a literature review on this issue with the objectives of (1) exploring the critical role that M\&E can play in enhancing the effectiveness of climate change mitigation and adaptation interventions in developing nations, (2) finding out the visibility of M\&E in climate change mitigation and adaptation work, (3) looking for evidence of $M \& E$ practices in climate change mitigation and adaptation interventions in developing nations, (4) identifying the missing gaps and (5) providing insights that practitioners need to design effective M\&E systems for climate change mitigation and adaptation interventions.

This article seeks to contribute to the literature as well as to debates on the application of M\&E practices and processes in dealing with climate change at various levels. The article begins with a conceptual review to explore the key concepts related to $M \& E$ and climate change mitigation and adaptation, then presents a brief overview of the problem of climate change. It also explores the critical role that M\&E can play in climate change mitigation and adaptation work, the visibility of M\&E in climate change mitigation and adaptation work as well as the evidence of its role in mitigation and adaptation interventions in developing nations. The readers will also identify the missing gaps in utilising M\&E for mitigation and adaptation work and get insights that practitioners need to design effective M\&E systems for climate change mitigation and adaptation work.

\section{Methodology}

This article was compiled based on Cooper's stages of literature review 1984 cited in Randolph (2009). According to Cooper 1984, conducting and reporting literature review follows five key stages: (1) identifying the rationale for the review, (2) developing key questions or hypotheses to guide the review, (3) coming up with a plan for collecting information or data including selection of units, (4) an explicit plan for analysis of literature reviewed and (5) a plan for presenting the findings. The researcher therefore followed this process to do literature review which informed the article and it is hereby explained briefly.

In the first stage, the researcher identified the rationale for the study in consultation with other experts in the area. A rationale for the review provides the purpose of the study and ultimately the paper. According to Locke et al. (2007) cited in Creswell (2009), the purpose indicates 'why you want to do the study and what you intend to accomplish'.
In the second stage, the researcher went on to develop research questions that would guide the review. The researcher based on experience and interest as well as the rationale for the review developed the research questions to guide the study, which are as follows: (1) What critical role can M\&E play in enhancing the effectiveness of climate change mitigation and adaptation interventions in developing nations? (2) What is the visibility of M\&E in mitigation and adaptation work in developing nations? (3) What evidence exists of M\&E practices in mitigation and adaptation interventions? (4) What are the missing gaps in M\&E practices currently implemented in mitigation and adaptation interventions in developing nations? (5) What insights do practitioners need to design effective M\&E systems for mitigation and adaptation interventions? These questions guided the review and collection of the information as well as analysis to inform the paper.

In the third stage, the researcher did the literature search to identify data to inform the paper. Literature search as a concept was explained by Gash (1999) cited in Ridley (2012) as 'a systematic and thorough search of all types of published literature in order to identify as many items as possible that are relevant to a particular topic'. Ridley argues that literature search serves several purposes including but not limited to, firstly, helping the researcher to 'identify the field and specific context in which your work is situated'; secondly, to 'find out what others have done in the area so as to avoid duplicating previous work'; and lastly, to 'identify key people, organizations and texts which are relevant to your research' (Ridley 2012:42-43). Therefore, the researcher came up with a plan to conduct a thorough literature search where relevant peer-reviewed articles and standard textbooks as well as grey literature were identified for the literature search. The researcher adopted the snowball technique in literature search. Ridley explains the snowball technique as one where, as you read articles or literature, 'you begin to recognize familiar authors and cited texts in the bibliographies of the books and articles you are reading'. Therefore, the technique involves following up on 'references from the bibliographies of texts you read'. The researcher also used several online search engines like Google Scholar, Eric and other websites for social research to identify online peer-reviewed articles on $\mathrm{M} \& \mathrm{E}$ and climate change mitigation and adaptation using key words and search terms. From a big volume of articles and online standard textbooks as well as eBooks, the researcher then came up with a criterion for inclusion and exclusion. The researcher used three of the components of Cooper's taxonomy of literature review, namely focus, goal and coverage, to select the most appropriate and relevant items for the review (Randolph 2009). Only literature that was related to these three components was included or selected for the review. In total, about 15 articles and a few textbooks as well as reports were selected for the review. The selected items were then thoroughly reviewed taking notes to inform the paper. The researcher ensured data quality using credible sources such as peer-reviewed journal articles and grey literature from credible international organisations. 
The fourth stage involved doing a thorough and critical reading of the literature that met the inclusion criteria to enable analysis. This step began with data evaluation. According to Randolph (2009), data evaluation requires the reviewer 'to extract and evaluate the information in the articles' and other types of literature 'that met the inclusion criteria'. The researcher then developed a code book for recording the extracted data according to the themes developed based on the objectives of the paper. The code book captured the type of data from each source, the process used to extract it and the actual data or information extracted from a particular source. The complete code book was then analysed using thematic analysis that enabled interpretation to make sense of the data or information from the review. Using thematic analysis framework provided by Braun and Clarke (2013), the researcher read through the articles to familiarise himself, then searched for themes, reviewed the candidate themes and identified relationships and finally came up with emerging findings on which the paper was based.

The last step was to come up with a plan for presenting the findings. The researcher developed an outline of the paper determining which information will be placed in each section of the paper. The format for the paper presentation was as follows: abstract, introduction, methodology, the key findings based on themes from the objectives, the discussion of key findings and then the conclusion and recommendations to practitioners as well as bibliography or references.

\section{Conceptual review Monitoring and evaluation}

Monitoring as a concept has been defined by several writers, and for the purpose of this article, the author will cite the definition by OECD (2002) cited in Imas and Rist (2009). According to them,

Monitoring is a continuous function that uses systematic collection of data on specified indicators to provide management and the main stakeholders of an ongoing development intervention with indications of the extent of progress and achievement of objectives and progress in the use of allocated funds. (p. 16)

Evaluation, on the other hand, has been explained by various authors. Weiss (1998) cited in Rabie and Goldman (2014) viewed the concept of evaluation as:

the systematic assessment of the operation and/or outcomes of a program or policy, compared to a set of explicit or implicit standards, as a means of contributing to the improvement of the program or policy. (p. 5)

Rabie and Goldman (2014) explained the stages of evaluation including:

identifying what was the intention, gathering data to describe the performance of the intervention being evaluated, synthesizing the data and integrating it in analysis of what was achieved compared to the intended objectives, analyzing why and how the results happened or did not happen and developing recommendations about how the intervention could be strengthened or possibly terminated. (p. 6)

For Imas and Rist (2009:8), evaluation refers to determining 'the value of a project, program or policy'. According to the authors, evaluation involves 'making a judgement of the value or worth of the subject of the evaluation'. All the authors cited above point to the fact that evaluation provides a systematic way to gain insights and reach judgement about effectiveness of programmes, validity of theories of change, utilisation of monitoring information or the impact of interventions on achievement of results. It is a way of learning and assessing the extent to which the intervention and its associated services met the needs of the beneficiaries within a manageable cost without serious side effects.

\section{Monitoring and evaluation system}

The M\&E system provides the environment through which M\&E processes can conducively take place within an organisation. The system offers managers and decisionmakers an additional management tool that provides feedback on performance of an intervention to enable them to learn, act and improve policies, programmes and projects both routinely and periodically.

Public agencies, private firms and voluntary organisations require a system that can help them track their performance and provide them with feedback on their management processes. Gorgens and Kusek (2009) argue that:

many management systems have been missing a feedback component to enable them to track the consequences of actions. Building an M\&E system gives decision makers an additional management tool by providing feedback on performance as a basis for future improvement. (p. 3)

The authors argue that 'a functioning M\&E system at any level provides a continuous flow of information that is useful internally and externally' providing 'information on progress, problems and performance to managers who are striving to achieve results' (Gorgens \& Kusek 2009:3).

Based on systems thinking, Gorgens and Kusek (2009:8) elaborately explained the 12 components of a functional M\&E system. According to them, a functional M\&E system is made up of (1) structure and organisational alignment for M\&E systems; (2) human capacity for M\&E systems; (3) M\&E partnerships; (4) M\&E plans; (5) costed M\&E work plans; (6) advocacy, communication and culture for M\&E systems; (7) routine monitoring; (8) periodical surveys; (9) databases useful to M\&E systems; (10) supportive supervision and data auditing; (11) evaluation and research; and (12) using information to improve results.

\section{Climate change}

One of the most cited definition of the concept of climate change is that of Intergovernmental Panel on Climate Change 
(IPCC) though there are many other authors that define the concept. Again for this article, the IPPC definition will be our guide. According to IPCC, climate change is defined as:

a change in the state of the climate that can be identified (e.g., using statistical tests) by changes in the mean and/or the variability of its properties, and that persists for an extended period, typically decades or longer. (Hegerl et al. 2007:667)

According to IPCC, climate change may be caused by nature or human factors. Natural processes may include, but are not limited to, volcanic eruptions, changes in solar radiation, etc., while human activities like land use and other activities that lead to emissions in the atmosphere are likely to cause climate change.

Nicholas Stern looks at climate change as the rapidly changing climate of the earth mainly because of the increase in greenhouse gases that come as a result of activities done by human beings (Stern 2008:4). This definition is rather more focused on the speed in the change of climate, but also emphasising the major cause of climate change as the increase in greenhouse gases caused by emissions in the atmosphere through human activities. He makes his point by acknowledging that 'an overwhelming scientific evidence indicates that the earth's climate is rapidly changing, predominantly as a result of increases in greenhouse gases caused by human activities'.

\section{Climate change mitigation}

Climate change mitigation is one of the strategies in dealing with the problem of climate change. All experts agree that climate mitigation can reduce the greenhouse gases that cause climate change variation. Anderson (2012) defines climate change mitigation as one that:

focuses on interventions to reduce greenhouse gas (GHG) concentrations through measures that cut GHG emissions or move carbon out of the atmosphere, which can range from investment in cleaner energies to forest conservation. (p. 192)

According to Anderson (2012), mitigation would significantly aim at tackling the main cause of climate change, increase in greenhouse emissions, to offset the likely effects of the problem on nature and human beings.

The IPCC also elaborately attempted to define the concept of climate mitigation. According to IPCC (2014), climate change mitigation is 'a human intervention to reduce the sources or enhance the sinks of greenhouse gases'. This definition like all the others implies that mitigation addresses the causes of climate change through human interventions. Again, the interventions will depend on what that group of human beings involved perceive to be the sources or sinks of these gases in that area.

\section{Climate change adaptation}

The concept of adaptation comes in the discussion of climate change as one of the strategies to address the problem of climate change. Again several writers attempt to define this concept from their own point of view. IPCC (2014) defines the term adaptation as 'the process of adjustment to actual or expected climate and its effects'. According to them, adaptation is about moderating or avoiding harm from the effects of climate change, and this can be done through interventions by various actors. The notion of climate change adaptation in this sense would include efforts to facilitate adjustment or resilience by those affected by the effects of climate change.

For Allison Anderson, it refers to 'reducing the vulnerability of natural and human systems to the impacts of climate change and adapting to a changing climate through adjustments in social, ecological or economic systems' (Anderson 2012). This definition attempts to look at the concept as a process of decreasing the level of exposure to effects of climate change for both nature and human beings. This process would enable the affected to adjust accordingly and therefore cope with the impact of climate change effects.

\section{A brief overview of the climate change problem}

The problem of climate change is no more a conceptual one but one that manifests in the real world. The IPCC report 2014 indicated that:

warming of the climate system is unequivocal, and since 1950s, many of the observed changes are unprecedented over decades to millennia. The atmosphere and oceans have warmed, the amounts of snow and ice have diminished, and sea level has risen. (p. 2).

Climate change and its effects are currently seriously biting economies from all sides. The effects span across several aspects of life including health, food supply and nutrition, housing, production and consumption systems, economic and social infrastructure, poverty and prosperity levels, etc.

Inter-Governmental Panel on Climate Change experts argue that in many regions, changing precipitation or melting snow and ice are altering hydrological systems, affecting water resources in terms of quantity and quality'. They continue to observe that 'many terrestrial, freshwater and marine species have shifted their geographical ranges, seasonal activities, migration, abundances and species interactions in response to ongoing climate change' (see IPPC 2014:6). The report also indicates extreme events that are now rampant across the globe including decrease in the number of cold days and nights, increase in the number of warm days and nights, increase in the frequency of heat waves, increase in heat-related human mortality and a decrease in coldrelated human mortality. Greater risks of flooding in several regions, droughts, cyclones and wildfires are increasingly being seen and recognised across the globe.

The world development report 2010 indicated that 'climate change threatens all countries, with developing countries the 
most vulnerable' (IBRD 2010). The report projected that global warming at $2{ }^{\circ} \mathrm{C}$ would result in a $4-5 \%$ reduction in GDP for developing countries in Africa and Asia (IBRD 2010:xx). The question is, what is causing this increase in greenhouse gas (GHG) emissions? To answer this question, IPCC (2014) indicated that between 1970 and 2010, emissions of $\mathrm{CO}_{2}$ from fossil fuel combustion and industrial processes did contribute $78 \%$ of GHG emissions. The highest level of emission according to the report was between 2000 and 2010 . This shows that human activity is the major contributor of GHG emissions and therefore climate change. The report attributes increase in anthropogenic GHG emissions to largely human economic activities as well as population growth. Stern (2008) argues that:

if greenhouse emissions remain at the current level, concentrations would be more than treble pre-industrial levels by 2100 , committing the world to $3-10^{\circ}$ warming based on the latest climate projections. (p. 5)

To address the problem of climate change and its effects, experts have prescribed two strategies, namely climate change mitigation and adaptation interventions across the globe. As mentioned above, climate change mitigation focuses on interventions to reduce GHG concentrations, while adaptation focuses on the process of decreasing the level of exposure to effects of climate change for both nature and human beings (Allison 2012).

\section{The critical role that monitoring and evaluation can play in climate change mitigation and adaptation work}

Monitoring and evaluation has been widely accepted as a key management tool in supporting the planning, implementation and performance of an intervention in any sector. Although the nonprofit sector as well as donor community has been at the forefront of promoting $\mathrm{M} \& \mathrm{E}$, the other two sectors, namely the private and public sectors, are increasingly adopting the M\&E practice in their operations given its benefits to the management functions. M\&E can play mainly four critical roles in an intervention, namely enhancing learning, supporting decision-making, a tool for accountability and helping organisations to improve. Each of these critical roles is discussed below in the context of climate change mitigation and adaptation.

\section{Enhancing learning}

Any organisation or agency that is involved in delivering projects, programmes or policies that focus on serving humanity must invest in learning from its actions. This is the rationale behind the concept of learning organisations. All that the organisation does and how it provides opportunities for learning or what other authors call knowledge capital. Kussek and Rist (2004) argue that:
Good M\&E systems are a source of knowledge capital. They enable governments and organizations to develop a knowledge base of the types of projects, programs and policies that are successful, and more generally what works, what does not and why. M\&E systems can also provide continuous feedback in the management process of monitoring and evaluating progress towards a given goal. In this context, they promote organizational learning. (p. 20)

In the context of climate change mitigation and adaptation interventions, practitioners or managers of these interventions need functional M\&E systems to enable them to generate knowledge capital for their programmes. At every stage of the intervention, M\&E generates data that may be analysed to generate lessons learnt. A deliberate effort needs to be made to ensure that the field staff who generate data routinely capture lessons learnt at every stage of the programme and that such lessons learnt feed into the implementation of the future activities and management processes. Without deliberate efforts to capture lessons learnt, the implementers and managers will not be able to incorporate these lessons into future activities, and therefore, improvements and innovations are not possible. Climate change mitigation and adaptation requires innovativeness and being strategic given the complexity of the climate change phenomenon. Therefore, M\&E can greatly play a key role in providing this muchneeded knowledge capital thus enhancing effectiveness of these interventions.

\section{Supporting decision-making}

Monitoring and evaluation is very critical in supporting decision-makers to make informed decisions. Decisionmakers at various levels including policymakers need evidence to make informed decisions at any level. Many policies and programmes are not well designed as well as implemented because of information deficiency leading to policy or programme failure. Decision-makers who make decisions based on evidence and reliable and valid M\&E data will enhance effectiveness and come up with practical solutions in addressing management problems or dilemmas routinely or periodically. Kussek and Rist (2004) noted that:

a functioning M\&E system provides a continuous flow of information that is useful both internally and externally. The internal uses come into play as the information from the M\&E system is used as a crucial management tool for the managers in achieving results and meeting specific targets. Information on progress, problems, and performance are all key to managers striving to achieve results. Likewise, information from an M\&E system is important to those outside the organization who are expecting results, wanting to see demonstrable impacts from actions and hoping to build trust in the organization that is striving to better the lives of its beneficiaries. (p. 19)

In the context of climate change mitigation and adaptation interventions, the M\&E system would greatly support informed decision-making at local, national, regional and international levels. Various decision-makers at all these levels need reliable and valid M\&E information to enable them to make informed, evidence-based decisions on what 
mitigation measures as well as adaptation interventions can effectively address climate change. The managers of these interventions will only be effective and innovative enough if they are supplied with M\&E information in a timely manner. Information on planned activities, targets, progress, challenges encountered, achievements and lessons learnt can be very handy and useful to managers, policymakers and other stakeholders who periodically and routinely make decisions regarding mitigation and adaptation interventions at local, national, regional and international levels.

\section{A tool for accountability}

Implementing units must account for the resources they use in their interventions as well as their actions. Stakeholders as well as donors need information on programmes and how they are being implemented. They also need information on how the funds and other resources are being utilised. Both external and internal stakeholders have information needs that the M\&E system can supply, depending on the specific information they need about the projects, programmes or policies being implemented with their support. Kussek and Rist (2004) noted that:

M\&E systems can also aid in promoting greater transparency and accountability within organizations and governments. Beneficial spillover effects may also occur from shining a light on results. External and internal stakeholders will have a clearer sense of the status of projects, programs and policies. (p. 20)

In the context of climate change mitigation and adaptation interventions, M\&E systems would support implementing agencies at various levels to report and account to governments, donors, legislators, economic groupings and expert organisations like IPCC. Routine data generated through the monitoring processes and periodical data generated through evaluations and periodical surveys on climate change mitigation and adaptation can inform stakeholders on progress, challenges, problems, financial and other resources utilisation, effectiveness of the interventions, policy changes that need to be made and lessons learnt that call for innovations and changes in implementation. Availability of such information to stakeholders would support transparency and accountability within the implementing units and therefore efficiency in the use of resources for mitigation and adaptation at various levels.

\section{Helping organisations to improve}

Monitoring and evaluation systems generate volumes of data that are analysed routinely and periodically to inform managers and other stakeholders. The M\&E system generates knowledge capital that is vital for managers and other decision-makers to reflect on what they do and their methods of work so that they create improvements routinely and periodically. Based on routine data, the managers and decision-makers can get insights on the operations and how best they can be improved. Improvements in funding modes, human resource allocation and utilisation, technological efficiency, effective implementation, service delivery and client or beneficiary absorption of services can only be achieved using information from the routine monitoring and periodic assessments and evaluations of interventions.

In the context of climate change mitigation and adaptation, M\&E would support implementers and other decisionmakers to reflect on the processes of their implementation and then look for ways to improve the programme design, delivery and programme products and services. The monitoring data can provide useful information on a routine basis that can inform decision-makers on how programmes are being implemented, the challenges faced, the opportunities that exist for better delivery of programme services and benefits and the consumption levels by beneficiaries. Evaluation data as well as periodical surveys can effectively inform managers and other decision-makers on efficiency, effectiveness, sustainability, relevance and impact of the climate change mitigation and adaptation projects, programmes or policies from which improvements on existing interventions or new improved ones can be developed.

Imas and Rist (2009) argue that:

Urgent issues such as climate change call for new approaches to evaluating sustainability. The scope of environmental problems, multinational consequences, difficulties in obtaining comparable measures, and persistent evidence of unanticipated consequences all necessitate a complex, multi method approach to evaluation. (p. 2)

This implies that innovative approaches to M\&E of climate change mitigation and adaptation interventions would significantly improve programmes.

\section{The visibility of monitoring and evaluation in climate change mitigation and adaptation work and missing gaps}

Despite the fact that many developing nations have and are implementing several climate change adaptation and mitigation interventions, many of these have no comprehensive M\&E systems. Ford et al. (2015:801) in their paper on the status of climate change adaptation in Africa and Asia did a systematic review of 'peer reviewed and grey literature as well as policy documents to extract evidence of adaptation initiatives in 47 vulnerable hotspot nations in Asia and Africa'.

The key findings from their analysis were that adaptation initiatives were predominantly being reported from African and low-income nations; the initiatives involved a combination of groundwork and more concrete adaptation actions; agriculture was the dominant focus of reported adaptation initiatives; and adaptation initiatives were being primarily driven at national level, with minimal involvement of lower levels of government or collaboration across nations. The findings also indicated that there is negligible 
consideration of vulnerable groups in adaptation initiatives and that the profile of adaptation initiatives differed between data sources (Ford et al. 2015:804-809).

Their analysis did not indicate existence of comprehensive M\&E systems but point to the fact that adaptation work reported in the 47 countries did not cover all sectors. Agriculture was the main sector where adaptation was reported. This indicates lack of comprehensive M\&E that covers other sectors though there is a possibility that the nations implemented adaptation initiatives in other sectors too. Also to note is that most of the adaptation reported was at national level and minimal at lower levels of government. This also points to the fact that M\&E was done at national level and not comprehensively done at lower levels despite the possibility that some initiatives were also implemented at lower levels of government.

Monitoring and evaluation will usually highlight issues of gender, inclusion of vulnerable groups and other aspects that cut across interventions. In their analysis, the authors reported that there was negligible consideration of vulnerable groups in adaptation initiatives. This also points to the missing gaps in M\&E of adaptation interventions within the countries that were reviewed.

Khan and Akhtar (2015) in their book chapter on agricultural adaptation and climate change policy for crop production in Africa concluded that:

\begin{abstract}
despite a considerable number of climate change adaptation research projects in the African region, there is little evidence regarding how the generated knowledge is made useful or integrated in the agricultural development plans of respective countries. (p. 524)
\end{abstract}

This supports the notion that M\&E of climate change adaptation and mitigation interventions has not been fully exploited. Ideally if there were comprehensive M\&E systems, such generated knowledge would be utilised and integrated into the planning process as well as decision-making at all levels. The authors also reported that 'little has been done to ensure that climate-resilient approaches are integrated into the sectors' (Khan \& Akhtar 2015:524). Again an effective M\&E system focuses on helping organisations to improve their interventions by supporting adoption of innovative and better approaches to deal with problems or situations. This was not the case according to the authors indicating a serious missing gap in the implementation of the adaptation interventions.

\section{Insights that practitioners need to design effective monitoring and evaluation systems for climate change mitigation and adaptation}

Effective M\&E systems for climate change mitigation and adaptation are needed urgently to enhance the effectiveness of the role that M\&E can play in enhancing effectiveness of mitigation and adaptation interventions especially in developing nations. In this article, the following insights are provided for practitioners to design and manage effective M\&E systems for climate change mitigation and adaptation interventions. These are discussed here briefly.

\section{Institutional arrangements for monitoring and evaluation}

To effectively design and manage an M\&E system for climate change mitigation and adaptation, practitioners need to put in place institutional arrangements for M\&E. Coning and Rabie (2014) argue that:

the institutional arrangements for monitoring and evaluation typically require: an assessment of the institutional readiness; development of M\&E policy and procedures; strong leadership understanding, support and commitment to the function; buyin, insight and support from managers; a progressive evaluation culture that is organization-wide; organizational and systems arrangements; clarity on M\&E related functions; specific human resources arrangements; capacity building and training; sound intergovernmental relations; and sound governance and participative arrangements. (p. 256)

A clear structure and organisational alignment for M\&E with clear roles and responsibilities of the M\&E unit as well as other units and individuals within the organisation implementing climate change mitigation and adaptation can be very handy in enhancing the role that M\&E can play in mitigation and adaptation efforts.

\section{Developing comprehensive monitoring and evaluation frameworks and plans for the interventions}

A comprehensive $M \& E$ framework and plan is key for climate change mitigation interventions. Gorgens and Kusek (2009) defined an M\&E plan as:

a comprehensive narrative document on all M\&E activities. It describes the key M\&E questions to be addressed; what indicators are to be measured; how, how often, from where and the indicator data that will be collected; baselines, targets and assumptions; how the data will be analyzed or interpreted and the frequency of reporting. (p. 145)

The benefits of having an M\&E framework and plan are enormous according to the authors. These may include providing a common vision of what a successful M\&E system will look like; providing a benchmark against which to measure progress in implementing the M\&E system; standardising and validating the mandates, authorities and responsibilities of M\&E stakeholders; assigning specific responsibilities to specific units within the organisation; providing a basis for deciding which M\&E activities to implement; and providing overall guidance on how M\&E will be executed in the organisation.

Such a document is key for monitoring and evaluating climate change mitigation and adaptation interventions because it would guide and support the M\&E unit in executing routine monitoring and periodic evaluation of the interventions. 


\section{Mobilisation of resources for monitoring and evaluation of interventions}

Monitoring and evaluation systems cannot function without financial and other resources. The implementing agencies need to explore avenues through which resources can be mobilised to fully support the M\&E unit. Such resources would ensure that the unit has adequate staffing, equipment and vehicles for routine and periodical data collection, Information and Communication Technology (ICT) equipment like computers, tablets, mobile handsets, data recorders, required software for data capture, analysis and interpretation, GIS and other needed packages for effective M\&E work. Resources for M\&E could be explored from various sources like donor agencies, NGOs, partnerships, foundations, think tanks, universities and individuals who can support the M\&E function financially, technically and logistically. Implementing agencies of climate change mitigation and adaptation need to strategically mobilise adequate resources for M\&E so that the quality of M\&E processes and outputs is not compromised.

\section{Human resources capacity building for monitoring and evaluation}

Monitoring and evaluation for climate change mitigation and adaptation interventions requires that the staff managing the M\&E system have the necessary skills to do their work. Gorgens and Kusek (2009) argue that:

The M\&E system cannot function without skilled people who effectively execute the M\&E tasks for which they are responsible. Therefore, understanding the skills needed and capacity of people involved in the M\&E system (undertaking human capacity assessments) and addressing capacity gaps (through structured capacity development programs) is at the heart of the M\&E system. (p. 94)

The practitioners therefore need to explore available opportunities for capacity building of M\&E staff that may range from conventional training, short-term training and mentorship programmes on M\&E. Coning and Rabie (2014) provide a wide range of capacity building support actions that include:

short or executive course training and post graduate studies, mentorship, learnerships and coaching, deliberate work exposure and on-job training, network development as well as volunteerism and scholarships. (p. 273)

\section{Creation of effective and relevant partnerships for monitoring and evaluation of interventions}

Effective M\&E systems require relevant partnerships that would support the M\&E function. Such partnerships could take the form of individuals, groups of individuals, experts, agencies and organisations. Gorgens and Kusek (2009) cite several benefits that accrue from M\&E partnerships. These include supporting coordination among other players outside the organisation; helping to simplify, harmonise and align the M\&E function with government and other development partners and frameworks; mobilising the required technical and financial support for implementing M\&E activities; helping to increase and improve communication within and outside the M\&E system; and undertaking joint missions or evaluations with other development partners.

Monitoring and evaluation for climate change mitigation and adaptation would be very effective with useful partnerships created. Partnerships with government agencies, foreign agencies, NGOs, think tanks, research and evaluation groups or organisations, universities and other higher education institutions, experts in M\&E and other institutions that can support the M\&E unit of implementing organisations could be explored. Such partnerships could add a lot of value to mitigation and adaptation interventions.

\section{Adoption of Information and Communication Technology and other software for monitoring and evaluation}

With the expansion of ICT almost across the globe, there is a huge potential for adoption of ICT in monitoring and evaluation processes and activities in various interventions at any level. M\&E practitioners continue to adapt their practices to ICT and mobile revolution. Bruce et al. (2014) highlight the emergency of technology-enabled monitoring and evaluation in Africa, emphasising the way in which ICT and mobile technology have provided innovative ways to approach M\&E globally. The authors give a wide range of advantages of mobile phone data collection, for example, over the traditional surveying including faster data collection, improved quality and accuracy of data and a 'possibility of immediate feedback on data collection challenges, monitoring of data collectors and viewing results online for decision making'. The authors also contend that 'mobile technology and online mapping resources have brought previously highly specialized GIS activities within reach of a much wider programme and M\&E user community' (Bruce et al. 2014:3). However, the authors noted that:

Many ICT enabled M\&E activities still frequently focus on data collection efforts. Yet there is much potential to use ICT across the whole spectrum of programme and M\&E activities: big data analysis, social monitoring and feedback loops, mapping and geolocation, strengthening randomized controlled trials (RCTs) and sharing M\&E information more effectively. (p. 3)

Practitioners in climate change mitigation and adaptation work need to adopt ICT and other M\&E enabled technology to ease their work and produce high-quality information for decision-making but also timely improvements on programme delivery.

\section{Promote effective utilisation of monitoring and evaluation information}

A comprehensive M\&E system without utilising the generated information for learning, acting and improving interventions does not make sense at all. It is a wastage of resources and effort. Kussek and Rist (2004) argue that: 
Using findings to improve performance is the main purpose of building a results-based M\&E system. The main point of the M\&E system is not simply to generate continuous results-based information but to get information to the appropriate users in a timely fashion so that the performance feedback can be used to better manage organizations and governments. (p. 138)

This implies that practitioners of climate change mitigation and adaptation need to ensure that the information generated through the M\&E system is put to effective use by managers and other decision-makers. M\&E information can be utilised in many ways, for example, when accounting for resources, during planning and formulation of budgets, during resource allocation decisions, using it to motivate human resources, using such information to support strategic planning and other management-related decision-making processes for the long run.

\section{Discussion and conclusion}

Throughout this article, it has been clearly shown that M\&E of climate change mitigation and adaptation interventions in developing nations remains to be fully utilised to enhance learning, inform decision-making and support improvements. The critical role that M\&E can play in climate change mitigation and adaptation has been highlighted comprehensively, clearly showing how the design and implementation of M\&E systems would generate knowledge for the implementing organisations and support decisionmaking at various levels by providing evidence-based information necessary for informed decision-making at management and governance levels.

The analysis has also shown that M\&E can be used as a tool for accountability, promoting transparency and other pillars of good governance, but also help organisations to improve on various practices like human resource allocation and utilisation, technological efficiency, implementation approaches and service delivery. The review has also clearly shown that M\&E is not adequately visible in climate change mitigation and adaptation interventions in developing nations, implying that there are serious missing gaps that need to be bridged by practitioners.

The analysis comprehensively provides insights that practitioners need to design effective M\&E systems for climate change mitigation and adaptation. These useful insights relate to the need for institutional arrangements for M\&E, developing comprehensive $M \& E$ frameworks and plans for the climate change mitigation and adaptation interventions, mobilisation of resources for M\&E of interventions, developing capacity of human resources for $M \& E$, creating effective and relevant partnerships for M\&E of interventions and adoption of ICT and other software for M\&E as well as coming up with ways to promote effective utilisation of M\&E information.
It is the prayer of the author that this article will widen the discussion on the role that $M \& E$ can play in supporting climate change mitigation and adaptation interventions in developing countries. It is also envisaged that this article will contribute to existing scholarly literature on $M \& E$ in the climate change mitigation and adaptation sector.

\section{Acknowledgements Competing interests}

The author declares that he has no financial or personal relationships that may have inappropriately influenced him in writing this article.

\section{References}

Anderson, A., 2012, 'Climate change education for mitigation and adaptation', Journa of Education for Sustainable Development 6, 197. https://doi.org/10.1177/ 0973408212475199

Braun, V. \& Clarke, V., 2013, Successful qualitative research: A practical guide for beginners, Sage, London.

Bruce, K., Khan, M., Vandelanotte, J., Mannino, C.A., Macpherson, N. \& Dickman, J., 2014, 'Reshaping development evaluation; Meeting the challenges of a changing context', African Evaluation Journal 2, 1-6. https://doi.org/10.4102/aej. v2i1.98

Coning, C.D. \& Rabie, B., 2014, 'Institutional arrangements for monitoring and evaluation', in F. Cloete, B. Rabie \& C.D. Coming (eds.), Evaluation management in South Africa and Africa, pp. 252-313, Sun Press imprint, Stellenbosch.

Creswell, J.W., 2009, Research design: Qualitative, quantitative and mixed methods approaches, Sage, Thousand Oaks, CA.

Ford, J.D., Berrang-Ford, L., Bunce, A., Mckay, C., Irwin, M. \& Pearce, T., 2015, 'The status of climate change adaptation in Africa and Asia', Regional Environmental Change 15, 801-814. https://doi.org/10.1007/s10113-014-0648-2

Gorgens, M. \& Kusek, J.Z., 2009, Making monitoring and evaluation systems work: A capacity development tool kit, The International Bank for Reconstruction and Development/The World Bank, Washington, DC.

Hegerl, G.C., Zwiers, F.W., Braconnot, P., Gillett, N.P., Luo, Y., Marengo Orsini, J.A. et al., 2007, 'Understanding and attributing climate change', in Climate change 2007: The physical science basis. Contribution of working, p. 667, Oxford University Press, New York.

IBRD, 2010, Development and climate change, The International Bank for Reconstruction/World Bank, New York.

Imas, L.G.M. \& Rist, R.C., 2009, 'The road to results: Designing and constructing effective development evaluations, World Bank, Washington, DC.

IPCC, 2014, Climate change 2014; Impacts, adaptation and vulnerability; Summary for policy makers; Phase 1 report launch, Intergovernment Panel on Climate Change, Paris.

Khan, M.A. \& Akhtar, M.S., 2015, 'Agricultural adaptation and climate change policy for crop production in Africa', in K.R. Hakeen (ed.), Crop production and global environmental issues, pp. 437-541, Springer International Publishing, Switzerland, Switzerland.

Kussek, J.Z. \& Rist, R.C., 2004, The ten steps to a results based monitoring and evaluation, World Bank Publications, Washington, DC

Rabie, B. \& Goldman, I., 2014, 'The context of evaluation management', in F. Cloete, B. Rabie \& C.D. Coning (eds.), Evaluation management in South Africa and Africa, $\mathrm{pp}$ 1-214, SUN MeDIA - SUN PRESS Imprint, Stellenbosch, South Africa.

Randolph, J.J., 2009, 'A guide to writing the dissertation literature review', Practical Assessment, Research \& Evaluation 14, 4

Ridley, D., 2012, The literature review: A step by step guide for students, Sage, Thousand Oaks, CA.

Stern, N., 2008, Economics of climate change; the stern review, Cambridge University Press, New York.

Wholey, J.S., Hatry, H.P. \& Newcomer, K.E., 2010, 'Preface', in J.S. Wholey, H.P. Hatry \& K.E. Newcomer (eds.), Handbook of practical program evaluation, pp. 1-700, Wiley, San Francisco, CA. 